\title{
Prevalence and associated factors of active trachoma among children in Ethiopia: a systematic review and meta-analysis
}

\author{
Alemu Gebrie $^{1 *} \mathbb{D}$, Animut Alebel ${ }^{2}$, Abriham Zegeye ${ }^{1}$, Bekele Tesfaye ${ }^{2}$ and Fasil Wagnew ${ }^{2}$
}

\begin{abstract}
Background: Trachoma is the commonest infectious cause of blindness. It is prevalent in areas where personal and community hygiene is poor, and it mainly affects deprived and marginalized communities most importantly in Ethiopia. Hence, the aim of this study was to determine the prevalence and associated factors of active trachoma among children in Ethiopia.

Method: A systematic review and meta-analysis was employed to determine the prevalence of active trachoma and associated factors among children in Ethiopia. We searched databases, including PubMed, Google Scholar, Science Direct, EMBASE and Cochrane Library. To estimate the prevalence, studies reporting the prevalence of active trachoma and its associated factors were included. Data were extracted using a standardized data extraction format prepared in Microsoft excel and the analysis was done using STATA 14 statistical software. To assess heterogeneity, the Cochrane $\mathrm{Q}$ test statistics and $P^{2}$ test were used. Since the included studies revealed considerable heterogeneity, a random effect meta- analysis model was used to estimate the pooled prevalence of active trachoma. Moreover, the association between factors and active trachoma were examined.
\end{abstract}

Results: The result of 30 eligible studies showed that the overall prevalence of active trachoma among children in Ethiopia was 26.9\% (95\% Cl: 22.7, 31.0\%). In the subgroup analysis, while the highest prevalence was reported in SNNP (35.8\%; 95\% Cl: 22.7, 48.8), the lowest prevalence was reported in Oromia region (20.2\%; 95\% Cl: 12.2, 28.2). Absence of latrine: OR 6.0 (95\% Cl 2.0, 17.5), the unclean faces of children: OR $5.5(95 \% \mathrm{Cl} 2.8,10.9)$, and no reported use of soap for washing: OR $3.3(95 \% \mathrm{Cl} 1.8,6.0)$ have shown a positive association with active trachoma among children.

Conclusion: From this review, it has been concluded that active trachoma among children is still a public health problem in different districts of Ethiopia. The prevalence of almost all studies are significantly higher than WHO target for elimination. Absence of latrine, unclean faces of children, no reported use of soap for washing are the important factors associated with active trachoma among children.

Keywords: Active trachoma, Associated factors, Children, Ethiopia

\footnotetext{
* Correspondence: alemugebrie2@gmail.com

${ }^{1}$ Department of Biomedical Science, School of Medicine, Debre Markos

University, P.O. Box 269, Debre Markos, Ethiopia

Full list of author information is available at the end of the article
}

(c) The Author(s). 2019 Open Access This article is distributed under the terms of the Creative Commons Attribution 4.0 International License (http://creativecommons.org/licenses/by/4.0/), which permits unrestricted use, distribution, and reproduction in any medium, provided you give appropriate credit to the original author(s) and the source, provide a link to the Creative Commons license, and indicate if changes were made. The Creative Commons Public Domain Dedication waiver (http://creativecommons.org/publicdomain/zero/1.0/) applies to the data made available in this article, unless otherwise stated. 


\section{Background}

Trachoma is caused by the bacterium Chlamydia trachomatis, which is the commonest infectious cause of blindness in our globe [1-4]. The disease can be transmitted by the discharge from infected eyes of individuals and transferred by fingers, eye-seeking flies or by clothes to the eyes of non-infected ones. Trachoma is prevalent in areas where personal and community hygiene is poor, and it mainly affects deprived and marginalized classes of a community [5, 6]. As per the 2018 report of WHO weekly epidemiologic record, the number of people living in districts where active trachoma was a public health problem was 157.7 million, $88 \%$ of which in Africa and $50 \%(69,802,693)$ of which in Ethiopia [7].

Africa remains the most affected continent, and the one with the most intensive control efforts. In 2017, in the 22 countries of WHO's Africa Region in which trachoma is known to be a public health problem, more than 226,000 people with trichiasis were given operations (95\% of the global total operated on for trichiasis), and more than 79 million people were treated with antibiotics $(95 \%$ of the global total given antibiotics for trachoma [https://www.who.int/news-room/fact-sheets/ detail/trachoma]. Considering it as a public health problem, Ethiopia had signed the VISION 2020 Initiative in 2002 and developed its own 20 years strategic plan to eliminate trachoma as a public health problem [8].

Although they vary among settings depending on economical, personal as well as environmental reasons, several factors are associated with an increased prevalence of trachoma. These include absence of hygiene and sanitation facilities and services, scarcity of water, living in trachoma endemic areas, overcrowded, living environment and poverty [9]. Studies conducted in Africa showed that children with ocular and nasal discharges were more likely to suffer from trachoma [10,11]. Either clean faces with eye seeking flies or unclean faces, time to fetch water, garbage in the compound, overcrowding, children with age $3-5$ years, less frequent face washing, presence of cattle in the household, open defecation, high fly density in the household are some of the factors associated with active trachoma in the studies [12-15].

The World Health Organization (WHO) in collaboration with other national health services and nongovernmental organizations (NGOs) started implementation of a program to eliminate trachoma as a public health problem (Global Elimination of Trachoma by 2020) [11]. The strategy of the program, termed as SAFE, comprises these control measures: Surgery for trichiasis (extremely painful condition), Antibiotics for infectious trachoma, Facial cleanliness to reduce transmission and Environmental improvement like control of disease transmitting eye seeker flies and the access to clean water [11].
In different regions of Ethiopia, several independent studies were conducted in children to assess the prevalence and associated factors of trachoma, but there was a great variation and inconsistency of the findings among the studies. To the best of our knowledge, the reasons for the variation of the prevalence and associated factors of trachoma in children in the studies have not yet been assessed. Hence, the aim of this systematic review and meta-analysis was to review and determine the prevalence and associated factors of active trachoma among children in Ethiopia. The results of the present study will help policy makers and other concerned bodies to plan and campaign for the improvement of programs aimed at trachoma prevention and eradication in the country. The study will also help researchers to carry out related studies with more interventional study designs. The review question is: What is the best available evidence on the prevalence and associated factors of active trachoma among children in Ethiopia?

\section{Methods}

\section{Study design and literature searching strategies}

This review was conducted to compile the most contemporary evidences using published articles as well as grey literature on the prevalence and associated factors of active trachoma among children in Ethiopia. For reporting, we followed the protocol of the Preferred Reporting Items for Systematic Reviews and Meta-Analyses (PRISMA) guideline [16]. Two approaches were followed to search potentially relevant studies. The electronic database search (PubMed, Google scholar, Science Direct, EMBASE, Cochrane library) and Google Scholar), and the manual search of references lists of previous prevalence studies to retrieve more related articles. "Associated factors", "Trachoma", "Active trachoma", "Children" and "Ethiopia" (see Additional file 1) were the key terms used for searching the articles in the reputable databases used both in separation and in combination using the Boolean operator like "OR" or "AND". The articles were searched from 15th September, 2017 to 31st December, 2018 and all the articles accessed until 31st December, 2018 were included in the study.

\section{Eligibility criteria Inclusion criteria}

The two investigators (AG and AA) independently and carefully reviewed the contents of each retrieved articles. Those literature fulfilling the following criteria were finally included in the study.

Population Studies done among children $($ age $<15)$ were considered. 
Study area Only those studies that were carried out in Ethiopia were included.

Study design Original articles that contain data reporting the prevalence and associated factors of active trachoma among children in Ethiopia were eligible.

Language Literature which have been published in English language were considered.

Publication condition Articles that met the criteria were considered irrespective of their publication status i.e. published, unpublished or grey literature).

\section{Exclusion criteria}

Three independent reviewers carried out the data extraction blindly after assessment of the abstracts and the full texts of the literature. Articles with problems in methods were excluded by the two independent researchers after reading the full text as well as abstracts. Because of incomplete data, full text inaccessible articles were not included in the review.

\section{Data extraction}

Using a pre-tested data extraction format, the necessary data were extracted by the investigators. The data extracted from the studies included: first author, region in the country where the study was conducted, the specific study area, study design, year of publication of the study, the sample size, response rate of the study and active trachoma prevalence. Any disagreements between the two authors on extraction of the data were settled through discussion and consensus. In addition, the variation was also resolved by involving third reviewer.

\section{Operational definitions of outcomes}

The prevalence of active trachoma (defined here as trachomatous inflammation-follicular or trachomatous inflammation-intense) among children was the main outcome of this review. The second outcome of the study was to assess the factors that are associated with active trachoma in children. In the included studies, we took the prevalence of trachoma in children that is adjusted by weighting the proportion of each 1-year age band observed to have TF by the proportion of the local 1-9-year-old population expected to have that age, according to the most recent census. The association between active trachoma and factors were examined through odds ratio. The odds ratio was calculated from the report of two by two Tables OR = ad/bc.

\section{Quality assessment}

To evaluate the quality of the studies, the authors used the Newcastle-Ottawa quality assessment tool Scale adapted for cross-sectional studies [17].. The tool has three indicators. The first section is graded out of five stars and assesses the quality of the methodology of a study. The second part of the tool is graded out of three stars and assesses the comparability of the studies. The last part of the tool is graded from two stars and measures the quality of the original articles with respect to their statistical analyses. Using the tool as a protocol two independent authors evaluated the quality of the original articles. Those studies with medium (fulfilling $50 \%$ of quality assessment criteria) and high quality ( $\geq 6$ out of 10 scales) were included for analysis. By taking the mean score of the two researchers, disagreements of their assessment results were resolved.

\section{Statistical analysis}

The necessary data were extracted from the studies using Microsoft Excel 2016 format and then analyzed by using STATA version 14.0 (STATA Corporation, College Station Texas) software respectively. The primary articles were summarized by using tables and the forest plot. The researchers calculated the standard error of prevalence of active trachoma for each original article using the binomial distribution formula. We checked heterogeneity among the reported prevalence of the studies by using Cochrane Q statistics and $\mathrm{I}^{2}$ test [18]. Heterogeneity is quantified as high (considerable), moderate, low with ranges of $75 \%$ or more, $50-75 \%$ and $25 \%$ or less for $\mathrm{I}^{2}$, respectively [19]. A random effects model was considered to estimate the Der Simonian and Laird's pooled effect since the test statistics showed there was a considerable heterogeneity among the studies $\left(\mathrm{I}^{2}=97.5 \%, p=0.000\right)$. Univariate meta-regression analysis was undertaken by taking the publication year and the sample size to identify the possible source (s) of heterogeneity and the authors found publication year to be statistically significant $(p=0.002)$. Potential publication bias was also assessed subjectively by funnel plot and objectively using Egger's weighted correlation and Begg's regression intercept tests at $5 \%$ significance level $[20,21]$. In Egger's and Begg's tests $p$-value $<0.05$ indicates the presence of publication bias while $p$-value $>$ 0.05 indicates that there is no publication bias. A funnel plot which is plotted by effect estimate (prevalence in this study case) versus standard error of effect estimate, is another subjective assessment of publication bias. Each dot represents a single study and symmetric dots of inverted funnel shape shows the absence of publication bias. If publication bias is noticed in the Randomeffects model, the estimate is determined by using Duval and Tweedie's Trim and Fill analysis. In addition, subgroup analysis was done using region of studies.in order to reduce the random heterogeneity between the estimates of the primary studies. 


\section{Results}

\section{Searching results}

The authors retrieved a total of 303 retrievals by search engines of databases. Because of duplications in the retrievals, 96 of them were excluded from inclusion. After evaluating the titles and abstracts, the rest 152 records, 207 retrievals were excluded because they were irrelevant for this meta-analysis regarding outcome of interest. Then, 55 full text articles were assessed for eligibility based on the consideration criteria. Finally, 30 studies were purported to be eligible for this systematic review and meta-analysis (Fig. 1).

From a total of 55 full text articles accessed, we rejected twenty of them because they were review studies, and /or conducted in other countries like: USA [22], China [23], India [24, 25], Nepal [26], Nigeria [27-29], Kenya [6, 3032], South Sudan [33, 34], Tanzania [35, 36], Senegal [37], Malawi [38-40], Mali [41], and Gambia [42]. Moreover, five full text articles [43-47] that have been conducted from various regions across Ethiopia were not included since their outcome estimates were different from prevalence of active trachoma in children which is the outcome of interest of this study, and they have been done in the adult population that is not the population of interest of the current study.

\section{Description of original studies}

The characteristics of the 30 primary studies included in this review has been described in Table 1. All of the studies were cross sectional study designs carried out in different parts of Ethiopia having sample size in a range of 267 in Dawro zone, Oromia region [67] to 62,869 in Amhara region [56]. These studies were conducted from 2005 to 2018. In the present meta-analysis, a total of 228,420 children were included to estimate the overall prevalence of active trachoma.

The 30 studies were conducted in different regions of the country: most of the studies were conducted in Amhara region: Amhara [48-57, 60], Tigray [73, 74], Harari [62], Oromia [63-67], Benishangul Gumuz [59], Afar [58], Somali [72], Gambella [61], Southern Nations, Nationalities and peoples' region (SNNPR) [12, 68-71] and one nationwide study [8]. Whereas the highest prevalence of active trachoma in children (59.2\%) was

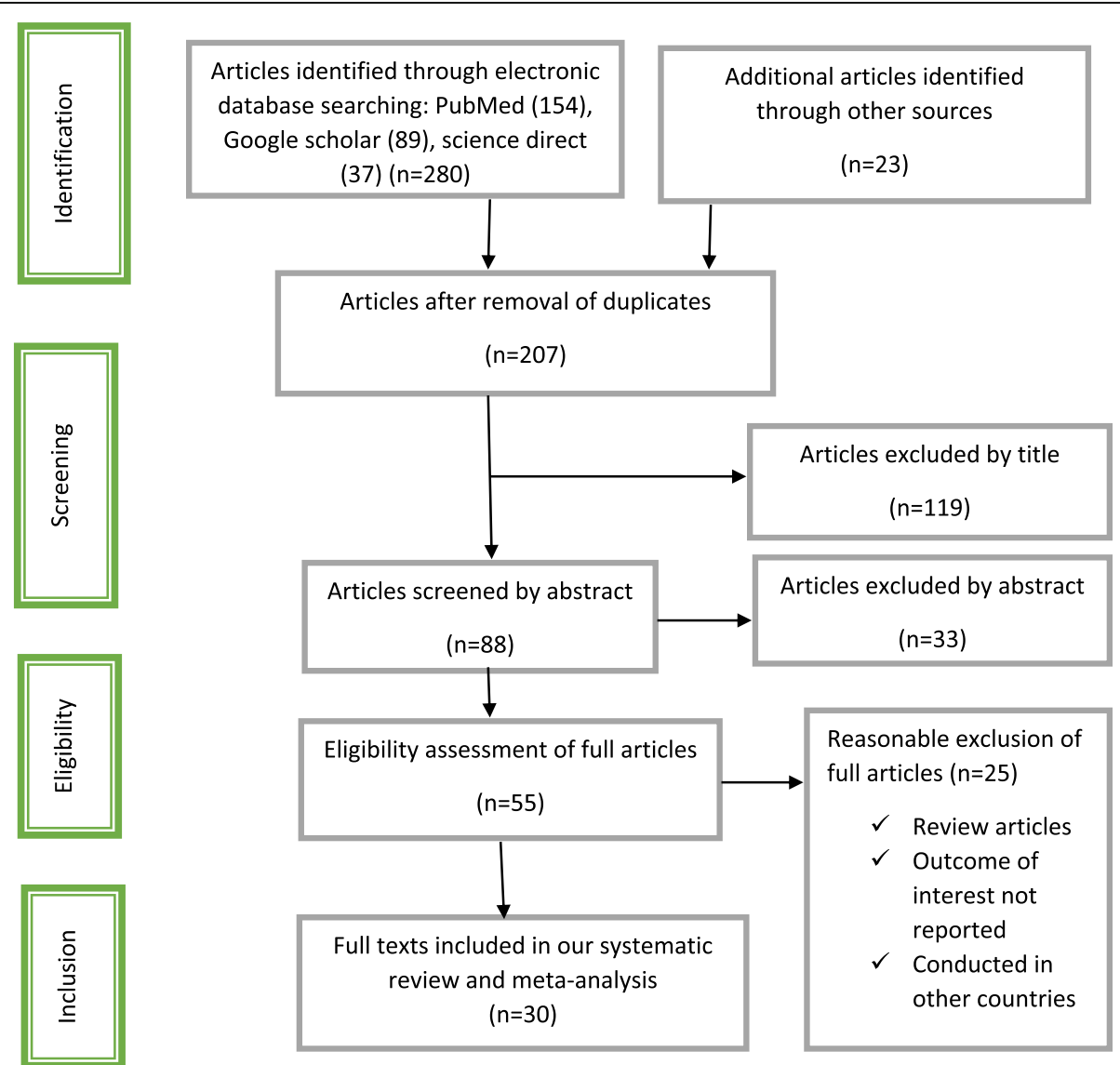

Fig. 1 Flow chart diagram describing selection of studies for the systematic review and meta-analysis of prevalence and associated factors of active trachoma among children in Ethiopia, 2018 (identified, screened, eligible and included studies). Articles may have been excluded for more than one reason 
Table 1 Descriptive summary of 30 studies reporting the prevalence and associated factors of active trachoma among children in. Ethiopia included in the systematic review and meta-analysis, 2018

\begin{tabular}{|c|c|c|c|c|c|c|c|}
\hline Region & Area & Author & $\begin{array}{l}\text { Publication } \\
\text { year }\end{array}$ & $\begin{array}{l}\text { Sample } \\
\text { size }\end{array}$ & $\begin{array}{l}\text { Response rate } \\
(\%)\end{array}$ & $\begin{array}{l}\text { Quality score (10 } \\
\text { pts) }\end{array}$ & $\begin{array}{l}\text { Prevalence (95\% } \\
\text { Cl) }\end{array}$ \\
\hline \multirow[t]{11}{*}{ Amhara } & Dembia District & Ferede et al [48] & 2017 & 681 & 98 & 7 & $18.2(15.3,21.3)$ \\
\hline & Baso Liben & Ketema et al. [49] & 2012 & 792 & 100 & 7 & $24.1(21.1,27.1)$ \\
\hline & Gazegibela & Anteneh and Getu [50] & 2016 & 601 & 100 & 8 & $52.4(48.4,56.4)$ \\
\hline & Wollo & Tadesse et al. [51] & 2017 & 1358 & 100 & 7 & $21.6(19.4,23.8)$ \\
\hline & Gonji Kolella & Nigusie et al. [52] & 2015 & 618 & 100 & 7 & $23.1(19.8,26.5)$ \\
\hline & Maksegnit & Shiferaw and Moges [53] & 2013 & 420 & 99.8 & 7 & $23.81(19.7,27.9)$ \\
\hline & ankober & Golovaty et al. [54] & 2009 & 510 & NR & 8 & $53.9(49.6,58.3)$ \\
\hline & Dangla & Gedefaw et al. [55] & 2013 & 409 & 100 & 6 & $12.0(8.8,15.1)$ \\
\hline & Belesa & Alemayehu & 2005 & 1244 & 100 & 7 & $42.4(39.6,45.1)$ \\
\hline & Regionwide & William Oswald et al. [56] & 2017 & 62,869 & 91 & 8 & $29.0(28.7,29.4)$ \\
\hline & Regionwide & Emerson et al. [57] & 2008 & 5485 & NR & 8 & $32.7(31.5,33.2)$ \\
\hline Afar & Regionwide & Negash et al. [58] & 2018 & 6399 & NR & 6 & $9.6(8.8,10.3)$ \\
\hline BG & Regionwide & Adamu et al. [59] & 2016 & 7417 & NR & 6 & $8.3(7.7,8.9)$ \\
\hline Dredawa & Dera Woreda & Metadel et al. [60] & 2015 & 671 & 96.5 & 8 & $15.7(12.9,18.4)$ \\
\hline Ethiopia & Nationwide & Birhane et al. [8] & 2006 & 9289 & NR & 6 & $40.1(39.2,41.1)$ \\
\hline Gambella & Regionwide & Abashawl et al. [61] & 2016 & 3238 & NR & 6 & $17.2(16.9,18.5)$ \\
\hline Harari & Harari region & Assefa et al. [62] & 2017 & 1722 & 93.8 & 6 & $1.3(0.8,1.8)$ \\
\hline \multirow[t]{6}{*}{ Oromia } & Mojo and Lume & Kassahun Yalew et al. [63] & 2012 & 431 & 100 & 5 & $22.5(18.6,26.5)$ \\
\hline & Kersa District & Meseret et al. [64] & 2013 & 305 & NR & 5 & $25.3(20.4,30.1)$ \\
\hline & butajira & Mehari [65] & 2014 & 735 & NR & 6 & $7.6(5.7,9.5)$ \\
\hline & Regionwide & Bero et al. [66] & 2016 & 41,642 & NR & 6 & $23.4(23.0,23.8)$ \\
\hline & Dawro Zone & Admasu W et al. [67] & 2015 & 267 & 100 & 6 & $22.9(17.8,27.9)$ \\
\hline & Regionwide & Adera et al. [68] & 2016 & 41,155 & NR & 6 & $28.3(27.9,48.8)$ \\
\hline \multirow[t]{4}{*}{ SNNP } & Zala district & Mengstu et al. [69] & 2016 & 611 & 98.87 & 7 & $36.7(32.8,40.5)$ \\
\hline & Goro district & Mohammed and Abebe [70] & 2005 & 826 & NR & 5 & $34.9(31.6,38.1)$ \\
\hline & Gurage & Admassu et al. [12] & 2013 & 768 & 97 & 8 & $22.8(19.8,25.8)$ \\
\hline & Gurage & Alemayehu et al. [71] & 2005 & 2788 & 95 & 7 & $56.5(54.7,58.3)$ \\
\hline Somali & Regionwide & Duale et al. [72] & 2018 & 23,620 & NR & 6 & $15.0(14.5,15.4)$ \\
\hline \multirow[t]{2}{*}{ Tigray } & Regionwide & Sherief et al. [73] & 2016 & 10,023 & NR & 6 & $26.7(25.8,27.5)$ \\
\hline & Regionwide & Mesfin et al. [74] & 2006 & 1526 & NR & 7 & $59.2(56.8,61.7)$ \\
\hline
\end{tabular}

reported in Tigray region by one-region wide study [74], a study conducted in Harari [62] reported the lowest prevalence $(1.28 \%)$ of the disease. Moreover, the original studies included in the meta-analysis and reporting response rate have had a response rate not less than $91 \%$ indicating that the studies have favorable response rate.

As far as the publication status of the studies is concerned: only one (Mesfin A: Assessing the prevalence of active trachoma among young children in relation to the implementation of safe strategy in EBINAT and EAST BELESA WOREDA, north West Ethiopia. unpublished) of the 30 studies was unpublished article (from Addis Ababa University digital repository library) and 29 of the studies included in the meta-analysis were searched by reproducible search from databases like PubMed. Independent evaluators re-assessed all the articles before any analysis and the studies were fit in terms of their quality (quality score ranged from 5 to 8 out of 10 points).

\section{Meta-analysis}

In this meta-analysis, the forest plot result of 30 included studies showed that the overall pooled prevalence of active trachoma among children in Ethiopia was 26.9\% (95\% CI: 22.7, 31, 0\%) (Fig. 2). Nevertheless, considerable heterogeneity was seen among the studies and objectively detected by $\mathrm{I}^{2}$ statistic $\left(\mathrm{I}^{2}=99.8, p\right.$ value $<0.000)$. Therefore, a random effect model was used to estimate the overall pooled prevalence of active trachoma 


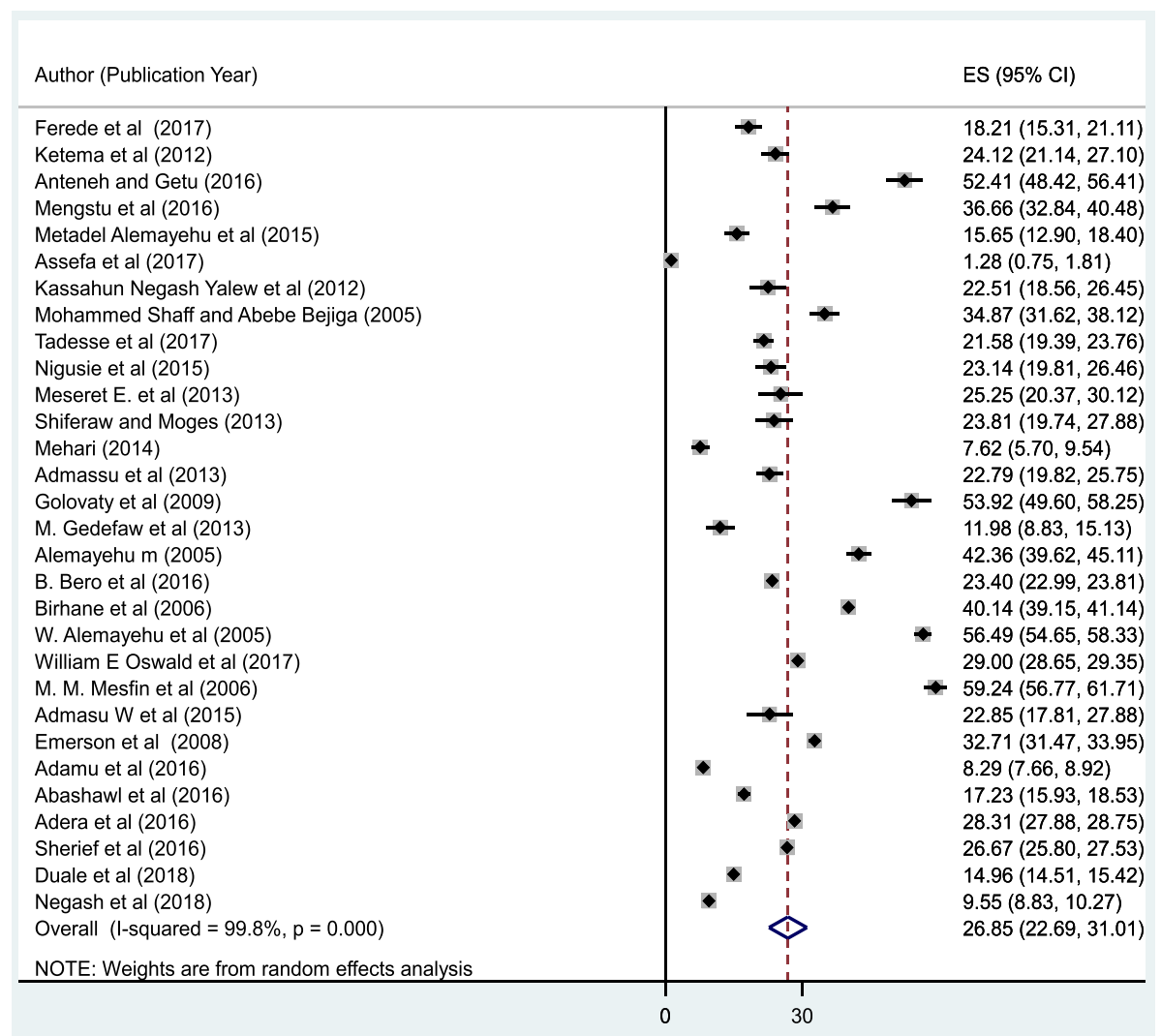

Fig. 2 Forest plot of the pooled prevalence of active trachoma among children in, 2018

among children in Ethiopia. To explore the possible sources of heterogeneity, different factors potentially associated with the heterogeneity, such as publication year and sample size were checked by using univariate meta-regression models and publication year was statistically significant $(p=0.001)$ (Table 2). Begg's and Egger's tests revealed the absence of statistically significant publication bias $(p=0.80)$ and $(p=$ 0.42 ) respectively. The funnel plot has also shown that the dots, representing the studies, were symmetrical that indicated the absence of publication bias (Fig. 3).

\section{Subgroup analysis}

In addition, in this meta-analysis, we performed subgroup analysis to explore sources of heterogeneity based on the region where the studies were conducted and publication years of the studies. Accordingly, the highest prevalence was reported in SNNP region with a prevalence of 35.8\%

Table 2 Related factors with heterogeneity of active trachoma prevalence among children in Ethiopia in the current metaanalysis (based on univariate meta-regression)

\begin{tabular}{lll}
\hline Variables & Coefficient & P-value \\
\hline Publication year & -3.582699 & 0.002 \\
Sample size & 0.000554 & 0.067 \\
\hline
\end{tabular}

(95\% CI: 22.9, 48.8) followed by Amhara region where most of the studies have been conducted, $30.2 \%$ (95\% CI: 25.7 , 34.7) and Others, $21.4 \%$ (95\% CI: 13.4, 29.4) (Table 3, Fig. 4). Concerning year of publication, the prevalence of active trachoma among children was significantly higher in studies which had been conducted before 2012 (32.7\%; 95\% CI: $24.8,40.6)$ as compared to those studies which have been carried out since 2012 (21.7, 95\% CI: 16.6, 26.8) (Table 3).

\section{Factors associated with active trachoma among children}

Using a total of eleven pre and post intervention surveys $[48-50,52,55,60,62,64,67,69]$ (Mesfin A: Assessing the prevalence of active trachoma among young children in relation to the implementation of safe strategy in EBINAT and EAST BELESA WOREDA, north West Ethiopia. unpublished) with data that can be analyzed, we meta-analyzed the associations of the absence of latrine, the facial cleanliness of children, and the reported use of soap with active trachoma among children in Ethiopia (Fig. 5). The researchers also performed sensitivity analysis in the factors analyses and found no significant outlier from the studies.

In the analysis of the six pre and post intervention studies, we have found that the absence of latrine 


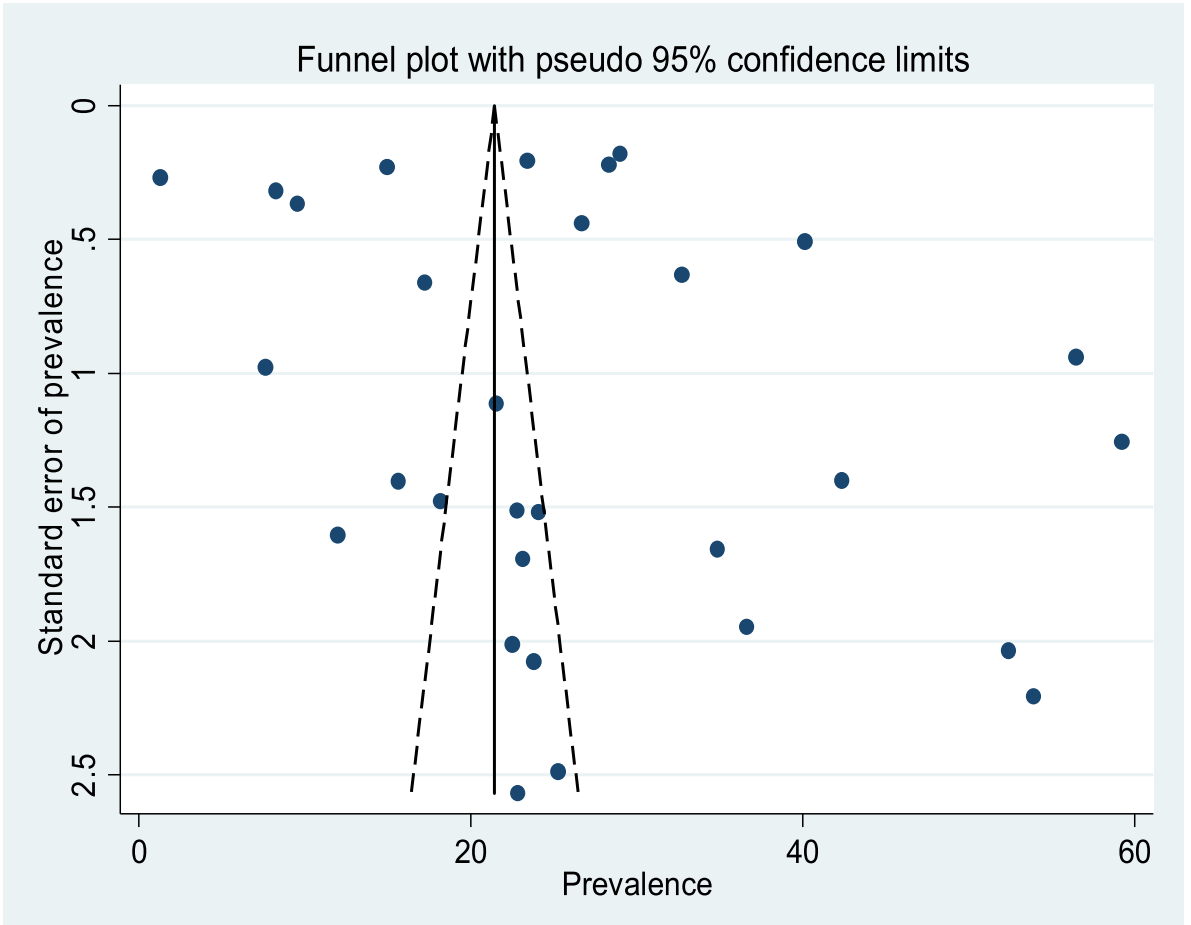

Fig. 3 The funnel plot of the meta-analysis containing 30 studies

was significantly associated with active trachoma among children, OR: 5.9 (95\% CI 2.0-17.5 Children who are living within the house of no latrine were 5.9 times more likely to have active trachoma as compared to those children who have access to functional latrine (Fig. 5a). The pooled result of seven studies also revealed that the facial cleanliness of children was strongly associated with active trachoma among children (Fig. 5b). Those children whose face has not been clean were 5.5 times more likely to have active trachoma as compared to their counterparts, odds ratio 5.5 (95\% CI 2.8,10.9).

In addition, results from the meta-analyses of three pre-intervention studies (Fig. 5c) have shown that no reported use of soap was a significant factor for active trachoma among children in Ethiopia. Children who failed to use soap for washing were about 3.3 times more

Table 3 Subgroup analysis of the prevalence active trachoma among children in Ethiopia, $2018(n=30)$

\begin{tabular}{llll}
\hline Variables & Characteristics & Number of studies & Prevalence with $95 \%$ \\
\hline Region & Oromia & 5 & $20.2(12.2,28.3)$ \\
& Amhara & 11 & $30.2(25.7,34.7)$ \\
& SNNP & 5 & $35.8(22.7,48.8)$ \\
& Others & 9 & $21.4(13.4,29.4)$ \\
Study year & $\leq 2012$ & 14 & $32.7(24.8,40.6)$ \\
& $>2012$ & 16 & $21.7(16.6,26.8)$ \\
\hline
\end{tabular}

likely to have active trachoma as compared to those children who reported using soap while washing their body, odds ratio 3.3 (95\% CI 1.8, 6.0).

Although they are not meta-analyzable, poor waste disposal, water inaccessibility, inadequate knowledge of family head about trachoma, keeping cattle near house, low monthly income and low altitude were also associated with active trachoma before and after interventions. Density of flies, illiteracy and using wood and animal dung for cooking were the factors associated with active trachoma in pre-intervention surveys. On the other hand, ocular discharge, family size, younger age and female sex were the factors associated with active trachoma in our systematic review of post intervention surveys.

\section{Discussion}

Trachoma remains a leading cause of preventable blindness in underprivileged communities in different parts of Africa most importantly in Ethiopia. The problem is worse if it is not detected and intervened early in children. This study aims to estimate the pooled prevalence of active trachoma and identify factors that are associated with it among children in Ethiopia. Using 30 relevant studies, this meta-analysis estimated that the prevalence of active trachoma among children in Ethiopia was $26.9 \%$, which is higher than WHO target for elimination $(<5 \%)$ in an evaluation unit of a country. In spite of 


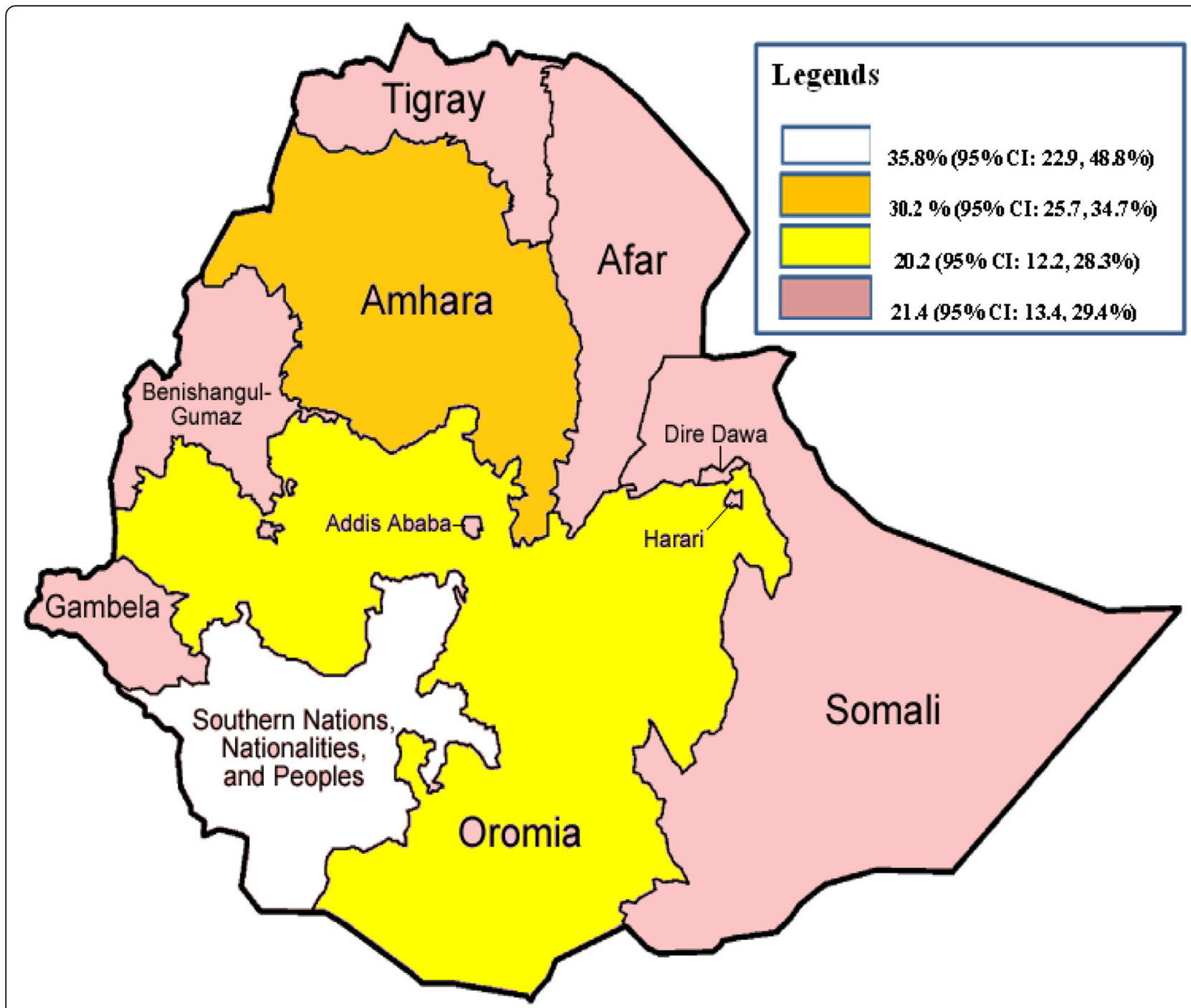

Fig. 4 The map showing the distribution of active trachoma in regions of Ethiopia

the fact that SAFE strategy (Surgery for trichiasis, Antibiotics for active disease, Facial cleanliness, and Environmental improvement) has been implemented in Ethiopia to reduce the spread of the disease, active trachoma is still a public health burden [8].

The possible plausible reason for the situation could be owing to scarcity of clean water supply in many areas of the community. Moreover, about $48 \%$ of the population lack functional latrine access and virtually all the community experience open field animal waste product disposal [75]. Another possible reason could also be that health education and health promotion on primary health care specifically on eye, personal as well as environmental hygiene and sanitation in the communities may not be satisfactory.

The subgroup analysis of this study also showed that the prevalence of active trachoma among children significantly varies across regions of Ethiopia. The prevalence was higher in children living in SNNP (37.7\%) and Amhara (30.2\%) regions as compared to other regions of the country. This pinpoints that despite SAFE strategy implementation in Amhara region, the disease is still in need of campaign and SNNP region is yet another part of Ethiopia where the SAFE strategy is to be feasibly implemented. With regard to study year, the prevalence of active trachoma was significantly lower in those studies conducted since 2012 as compared to those studied before 2012. We hypothesize that this difference is due to implementation of the SAFE strategy in Amhara region. Other potential explanations include the (1) more heavily-endemic areas were surveyed first, because that was where the greatest need was perceived, and (2) different survey methodologies and methods of analysis. Nearly all surveys undertaken in Ethiopia since 2012 have used highly quality-controlled and quality assured methodologies [76]. 


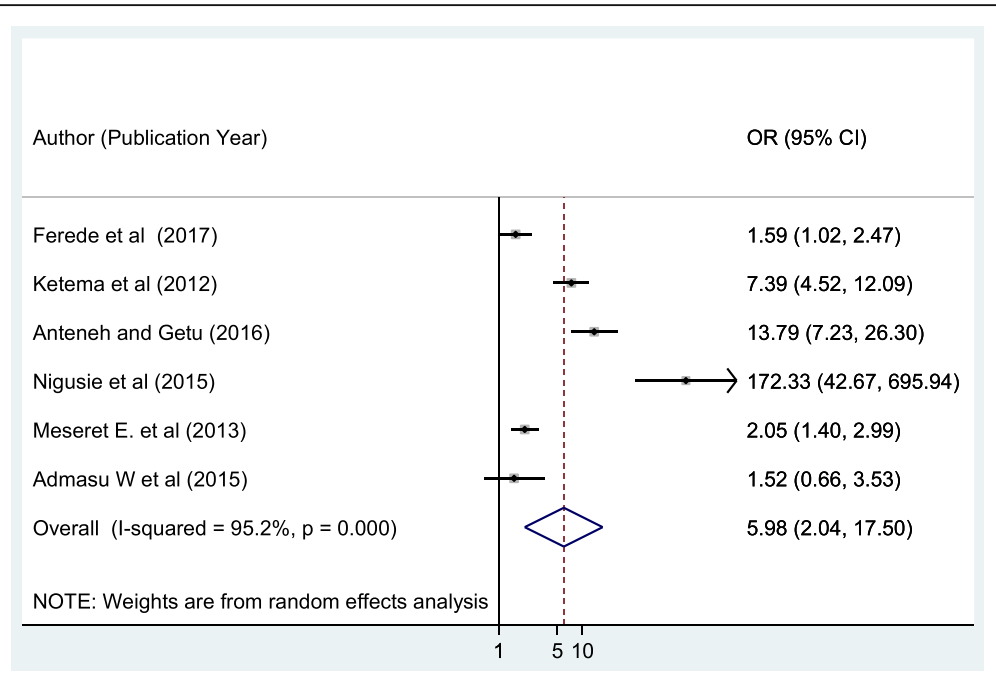

A

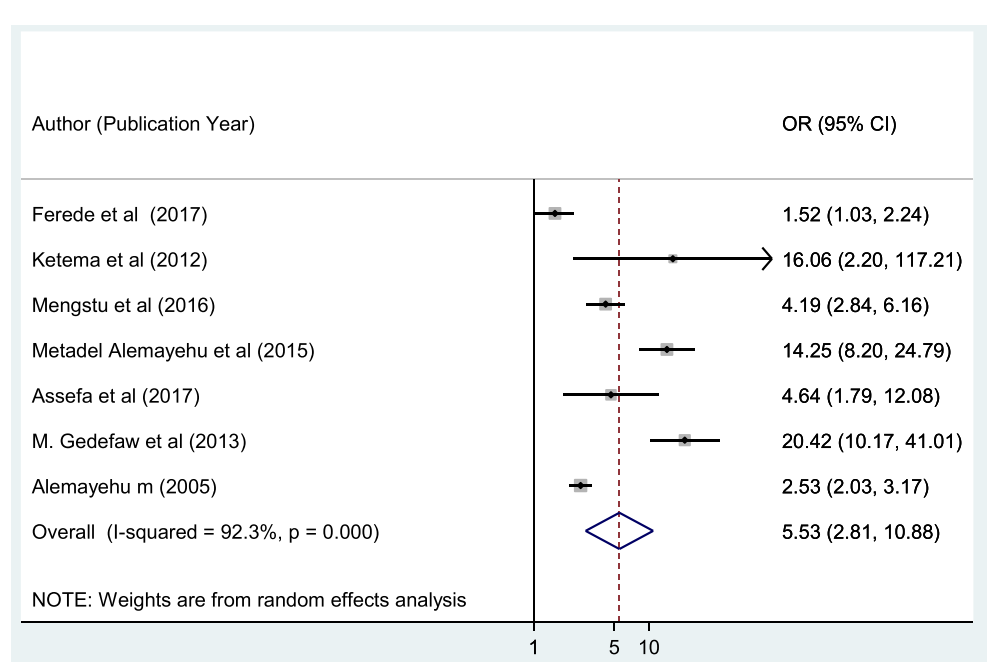

B

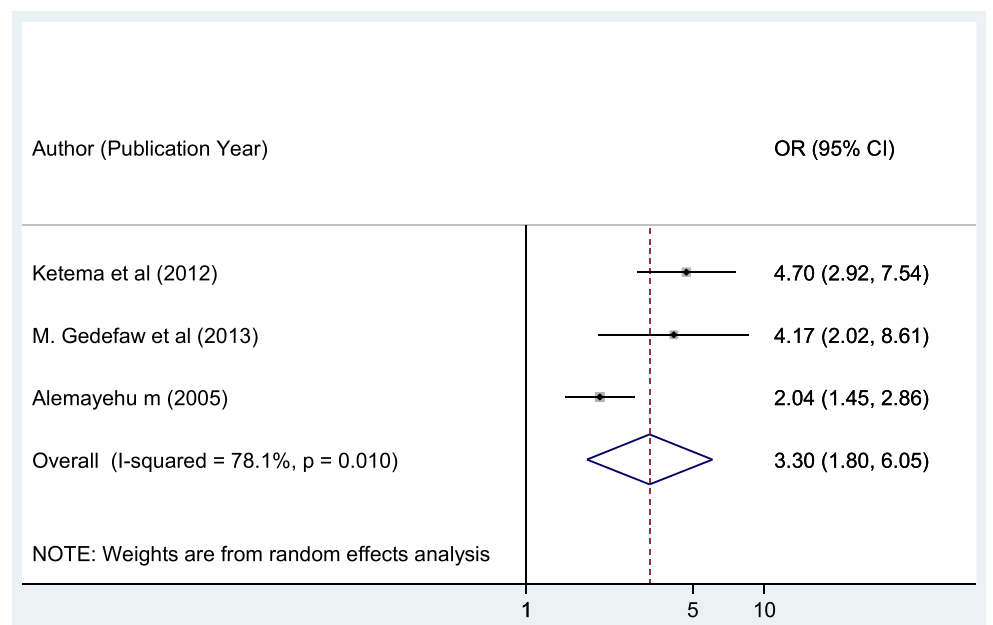

C

Fig. 5 Forest plot depicting pooled odds ratio (log scale) of the associations between active trachoma among children in Ethiopia and its purported associated risk factors $\mathbf{a}$ : Absence of latrine, $\mathbf{b}$ : Face uncleanliness of children, $\mathbf{c}$ : No usage of soap) 
We have also systematically reviewed and metaanalyzed the factors associated with active trachoma among children that have been addressed by the included studies. In the studies that examined the associated factors, presence of latrine, facial cleanliness and reported use of soap were meta-analyzable, and significantly associated with prevalence of active trachoma among children. Children that are from families who did not use latrine were 6.0 times more likely to be infected by active trachoma than those children with families who had access to functional latrine. This finding is in trajectory with a study carried out by WHO [77]. This could be reasoned out that inadequate disposal of waste materials is a factor for the presence of high number of eyes seeking flies that leads to a high chance of transmission of active trachoma.

Facial cleanliness of the children was also significantly associated with the development of active trachoma. Children with unclean faces were 5.5 more likely to have trachoma than those children whose faces were clean. The finding is concordant to a study identifying the presence of nasal and ocular discharge as factors for the presence of flies on eyes and active trachoma in Gambia and Tanzania [10]. The possible explanation is because of the fact that unclean faces attract eye-seeking flies which are potential mechanical vectors of Chlamydia trachomatis infection [78]. Nasal and ocular discharges may both result from the inflammation of active trachoma and cause the face to be classified as unclean $[22,79,80]$.

Moreover, the result of this study (review of preintervention surveys) showed that face washing using soap has a protective association against active trachoma among children. Children who were not using soap while washing their face were 3.3 times more likely to suffer from trachoma than those children who were using soap during face washing.

\section{Conclusions}

From this review, it has been concluded that active trachoma among children is still a public health problem in different districts of Ethiopia although Ethiopia signed the VISION 2020 Initiative in 2002 and developed its own 20 years' strategic plan to eliminate trachoma as a public health problem. The prevalence of almost all studies are significantly higher than WHO target for elimination. Absence of latrine, facial uncleanliness and no reported use of soap for washing are factors associated with active trachoma among children. Therefore, based on our findings, we recommend that the government and other concerned bodies shall undertake successful SAFE strategy implementation integrated with health education and health promotion to prevent and eliminate trachoma as a public health problem from the country.

\section{Supplementary information}

Supplementary information accompanies this paper at https://doi.org/10. 1186/s12879-019-4686-8

Additional file 1. Searching approach for PubMed

Abbreviations

BG: Benshangul Gumuz; PRISMA: Preferred Reporting Items of Systematic Reviews and Meta-Analysis; SNNPE: Southern Nations, Nationalities and peoples of Ethiopia; USA: United States of America; WHO: World Health Organization

\section{Acknowledgments}

Not applicable.

\section{Authors' contributions}

AG: Conception of research protocol, study design, literature review, data extraction, data analysis, interpretation and drafting the manuscript. AA, AZ, BT and FW: Data extraction, analysis and reviewing the manuscript and quality assessment. All the authors have read and approved the manuscript.

Funding

We have not obtained any fund for this study.

Availability of data and materials

All relevant data are within the paper and its Supporting Information files.

Ethics approval and consent to participate

Not applicable.

Consent for publication

Not applicable.

\section{Competing interests}

The authors declare that they have no competing interests.

\section{Author details}

${ }^{1}$ Department of Biomedical Science, School of Medicine, Debre Markos University, P.O. Box 269, Debre Markos, Ethiopia. ${ }^{2}$ Department of Nursing, College of Health Sciences, Debre Markos University, Debre Markos, Ethiopia.

Received: 9 October 2018 Accepted: 8 December 2019

Published online: 21 December 2019

References

1. Burton MJ, Mabey DC. The global burden of trachoma: a review. PLoS Negl Trop Dis. 2009;3(10):e460.

2. Cromwell E, Emerson P, Courtright P: Women and trachoma: achieving gender equity in the implementation of SAFE, February 2009. The Carter Center, Kilimanjaro Centre for Community Ophthalmology, The Elfenworks Foundation 2009.

3. Pascolini D, Mariotti SP. Global estimates of visual impairment: 2010. Br J Ophthalmol. 2012;96(5):614-8.

4. World Health Organization: Global Initiative for the Elimination of Avoidable Blindness: action plan 2006-2011. 2007.

5. Habtamu E, Wondie T, Aweke S, Tadesse Z, Zerihun M, Zewdie Z, Callahan K, Emerson PM, Kuper H, Bailey RL. Trachoma and relative poverty: a casecontrol study. PLoS Negl Trop Dis. 2015;9(11):e0004228.

6. Karimurio J, llako D, Adala H, Gichangi M, Kilima P. Prevalence of trachoma in six districts of Kenya. East Afr Med J. 2006;83(4):63-8.

7. World Health Organization. WHO Alliance for the global elimination of trachoma by 2020: progress report on elimination of trachoma 2017. Wkly Epidemiol Rec. 2018;93(26):371-80.

8. Berhane Y, Worku A, Bejiga A. National survey on blindness, low vision and trachoma in Ethiopia. Fed Minist Health Ethiop. 2006

9. World Health Organization. Global WHO Alliance for the elimination of blinding trachoma by $2020=$ Alliance mondiale de l'OMS pour l'élimination du trachome cécitant d'ici l'an 2020. Wkly Epidemiol Rec. 2012;87(17):161-8.

10. Harding-Esch EM, Edwards T, Mkocha H, Munoz B, Holland MJ, Burr SE, Sillah A, Gaydos CA, Stare D, Mabey DC. Trachoma prevalence and associated risk 
factors in the Gambia and Tanzania: baseline results of a cluster randomised controlled trial. PLoS Negl Trop Dis. 2010;4(11):e861.

11. Last AR, Burr SE, Weiss HA, Harding-Esch EM, Cassama E, Nabicassa M, Mabey DC, Holland MJ, Bailey RL. Risk factors for active trachoma and ocular chlamydia trachomatis infection in treatment-naive trachoma-hyperendemic communities of the Bijagos archipelagoGuinea Bissau. PLoS Negl Trop Dis. 2014;8(6):e2900.

12. Admassu F, Bayu S, Bejiga A, Amare B. Active trachoma two years after three rounds of azithromycin mass treatment in Cheha district Gurage zone Southern Ethiopia. BMC Pediatr. 2013;13(1):199.

13. Baggaley R, Solomon A, Kuper H, Polack S, Massae P, Kelly J, Safari S, Alexander $\mathrm{N}$, Courtright $\mathrm{P}$, Foster A. Distance to water source and altitude in relation to active trachoma in Rombo district Tanzania Trop. Med Int Health. 2006;11(2):220-7.

14. Mpyet C, Goyol M, Ogoshi C. Personal and environmental risk factors for active trachoma in children in Yobe state, North-Eastern Nigeria. Tropical Med Int Health. 2010;15(2):168-72.

15. Ngondi J, Gebre T, Shargie EB, Graves PM, Ejigsemahu Y, Teferi T, Genet A, Mosher AW, Endeshaw T, Zerihun M. Risk factors for active trachoma in children and trichiasis in adults: a household survey in Amhara regional state, Ethiopia. Trans R Soc Trop Med Hyg. 2008;102(5):432-8.

16. Liberati A, Altman DG, Tetzlaff J, Mulrow C, Gøtzsche PC, loannidis JP, Clarke M, Devereaux PJ, Kleijnen J, Moher D. The PRISMA statement for reporting systematic reviews and meta-analyses of studies that evaluate health care interventions: explanation and elaboration. PLoS Med. 2009; 6(7):e1000100.

17. Newcastle-Ottawa: Scale customized for cross-sectional studies. In. available from https://www.static-contentspringfcom/esm//12889_2012_5111_ MOESM3_ESM.doc.

18. Rücker G, Schwarzer G, Carpenter J, Schumacher M. Undue reliance on 12 in assessing heterogeneity may mislead. BMC Med Res Methodol. 2008;8(79).

19. Higgins J, Thompson S: Quantifying heterogeneity in a meta-analysis Stat med 21(11): 1539-1558. Find this article online 2002.

20. Sterne J, Egger M. Funnel plots for detecting bias in meta-analysis: guidelines on choice of axis. J Clin Epidemiol. 2001;54:1046-55.

21. Egger M, Smith GD, Schneider M, Minder C. Bias in meta-analysis detected by a simple, graphical test. BMJ Open. 1997;315:629-34.

22. Stocks ME, Ogden S, Haddad D, Addiss DG, McGuire C, Freeman MC. Effect of water, sanitation, and hygiene on the prevention of trachoma: a systematic review and meta-analysis. PLoS Med. 2014;11(2):e1001605.

23. Xue W, Lu L, Zhu J, He X, He J, Zhao R, Zou H. A cross-sectional populationbased survey of trachoma among migrant school aged children in Shanghai China. BioMed Res Int. 2016;2016.

24. Malhotra S, Vashist P, Gupta N, Kalaivani M, Satpathy G, Shah A, Krishnan S, Azad R. Prevalence of trachoma in car-Nicobar Island, India after three annual rounds of mass drug administration with azithromycin. PLoS One. 2016;11(7):e0158625.

25. Vashist P, Gupta N, Rathore AS, Shah A, Singh S. Rapid assessment of trachoma in underserved population of car-Nicobar Island India. PLoS One. 2013;8(6):e65918.

26. Katz J, West KP, Khatry SK, LeClerq SC, Pradhan EK, Thapa M, Shrestha SR, Taylor HR. Prevalence and risk factors for trachoma in Sarlahi district Nepal. Br J Ophthalmol. 1996;80(12):1037-41.

27. Mpyet $C$, Lass $B D$, Yahaya $H B$, Solomon AW. Prevalence of and risk factors for trachoma in Kano state Nigeria. PLoS One. 2012;7(7):e40421.

28. Mpyet C, Muhammad N, Adamu MD, Muazu H, Umar MM, Abdull M, Alada J, Goyol M, Onyebuchi U, Olamiju F. Prevalence of Trachoma in Bauchi State, Nigeria: Results of 20 Local Government Area-Level Surveys. Ophthalmic Epidemiol. 2016;23(sup 1):39-45.

29. Mpyet C, Muhammad N, Adamu MD, Muazu H, Umar MM, Goyol M, Yahaya $\mathrm{HB}$, Onyebuchi U, Ogoshi C, Hussaini T. Prevalence of trachoma in Kano state, Nigeria: results of 44 local government area-level surveys. Ophthalmic Epidemiol. 2017;24(3):195-203.

30. Whitfield R, Schwab L, Ross-Degnan D, Steinkuller P, Swartwood J. Blindness and eye disease in Kenya: ocular status survey results from the Kenya rural blindness prevention project. Br J Ophthalmol. 1990;74(6):333-40.

31. Schwab L, Whitfield R, Ross-Degnan D, Steinkuller P, Swartwood J, Group SS, Adala H, Bakker N, Beekhuis H, Bisley G. The epidemiology of trachoma in rural Kenya: variation in prevalence with lifestyle and environment. Ophthalmol. 1995;102(3):475-82.
32. Ilako F, Gichangi M. Prevalence of active and potentially blinding trachoma in Laikipia district, Kenya. JOECSA. 2013;13(3).

33. Edwards T, Smith J, Sturrock HJ, Kur LW, Sabasio A, Finn TP, Lado M, Haddad D, Kolaczinski JH. Prevalence of trachoma in Unity state, South Sudan: results from a large-scale population-based survey and potential implications for further surveys. PLoS Negl Trop Dis. 2012;6(4):e1585.

34. King JD, Ngondi J, Gatpan G, Lopidia B, Becknell S, Emerson PM. The burden of trachoma in ayod county of southern Sudan. PLoS Negl Trop Dis. 2008;2(9):e299.

35. Zambrano Al, Muñoz BE, Mkocha H, West SK. Exposure to an indoor cooking fire and risk of trachoma in children of Kongwa Tanzania. PLoS Negl Trop Dis. 2015;9(6):e0003774.

36. Wedner SH, Ross DA, Balira R, Kaji L, Foster A. Prevalence of eye diseases in primary school children in a rural area of Tanzania. Br J Ophthalmol. 2000; 84(11):1291-7.

37. Harding-Esch EM, Kadimpeul J, Sarr B, Sane A, Badji S, Sillah A, Burr SE, MacLeod D, Last AR, Holland MJ. Population-based prevalence survey of follicular trachoma and trachomatous trichiasis in the Casamance region of Senegal. BMC Public Health. 2018;18(1):62.

38. Kalua K, Chirwa T, Kalilani L, Abbenyi S, Mukaka M, Bailey R. Prevalence and risk factors for trachoma in central and southern Malawi. PLoS One. 2010;5(2):e9067.

39. Kalua K, Phiri M, Kumwenda I, Masika M, Pavluck AL, Willis R, Mpyet C, Lewallen S, Courtright P, Solomon AW. Baseline trachoma mapping in Malawi with the global trachoma mapping project (GTMP). Ophthalmic Epidemiol. 2015;22(3):176-83.

40. Gilliams EA, Jumare J, Claassen CW, Thesing PC, Nyirenda OM, Dzinjalamala FK, Taylor T, Plowe CV, Tracy LA, Laufer MK. Chloroquine-azithromycin combination antimalarial treatment decreases risk of respiratory-and gastrointestinal-tract infections in Malawian children. J Infect Dis. 2014;210(4):585-92.

41. Bamani S, King JD, Dembele M, Coulibaly F, Sankara D, Kamissoko Y, Ting J, Rotondo LA, Emerson PM. Where do we go from here? Prevalence of trachoma three years after stopping mass distribution of antibiotics in the regions of Kayes and Koulikoro Mali. PLoS Negl Trop Dis. 2010;4(7):e734.

42. Burton MJ, Holland MJ, Makalo P, Aryee EA, Sillah A, Cohuet S, Natividad A, Alexander ND, Mabey DC, Bailey RL. Profound and sustained reduction in chlamydia trachomatis in the Gambia: a five-year longitudinal study of trachoma endemic communities. PLoS Negl Trop Dis. 2010;4(10):e835.

43. Melese M, Alemayehu W, Bayu S, Girma T, Hailesellasie T, Khandekar R, Worku A, Courtright P. Low vision and blindness in adults in Gurage zone, Central Ethiopia. Br J Ophthalmol. 2003;87(6):677-80.

44. West SK, West ES, Alemayehu W, Melese M, Munoz B, Imeru A, Worku A, Gaydos C, Meinert CL, Quinn T. Single-dose azithromycin prevents trichiasis recurrence following surgery: randomized trial in Ethiopia. Arch Ophthalmol. 2006;124(3):309-14.

45. Bejiga A, Alemayehu W. Prevalence of trachoma and its determinants in Dalocha District Central. Ethiopia Ophthalmic Epidemiol. 2001;8(2-3):119-25.

46. Porco TC, Gebre T, Ayele B, House J, Keenan J, Zhou Z, Hong KC, Stoller N, Ray KJ, Emerson P. Effect of mass distribution of azithromycin for trachoma control on overall mortality in Ethiopian children: a randomized trial. JAMA. 2009:302(9):962-8.

47. Zerihun N. Impact of trachoma among rural Ethiopian women. Ethiop J Health Sci. 1998;8(1):53-9.

48. Ferede AT, Dadi AF, Tariku A, Adane AA. Prevalence and determinants of active trachoma among preschool-aged children in Dembia District Northwest Ethiopia. Infect Dis Poverty. 2017;6(1):128.

49. Ketema K, Tiruneh M, Woldeyohannes D, Muluye D. Active trachoma and associated risk factors among children in Baso Liben District of East Gojjam Ethiopia. BMC Public Health. 2012;12(1):1105.

50. Anteneh ZA, Getu WY. Prevalence of active trachoma and associated risk factors among children in Gazegibela district of Wagehemra Zone, Amhara region, Ethiopia: community-based cross-sectional study. Trop Dis Travel Med Vaccines. 2016;2(1):5.

51. Tadesse B, Worku A, Kumie A, Yimer SA. The burden of and risk factors for active trachoma in the north and south Wollo zones of Amhara region, Ethiopia: a cross-sectional study. Infect Dis Poverty. 2017;6(1):143.

52. Nigusie A, Berhe R, Gedefaw M. Prevalence and associated factors of active trachoma among childeren aged 1-9 years in rural communities of Gonji Kolella district, West Gojjam zone North West Ethiopia. BMC Res Notes. 2015; 8(1):641. 
53. Shiferaw D, Moges HG. Risk factors for active trachoma among children aged 1-9 years in Maksegnit town, Gondar Zuria District Northwest Ethiopia. Risk. 2013;2(3):202-6.

54. Golovaty I, Jones L, Gelaye B, Tilahun M, Belete H, Kumie A, Berhane Y, Williams MA. Access to water source, latrine facilities and other risk factors of active trachoma in Ankober Ethiopia. PLoS One. 2009:4(8):e6702.

55. Gedefaw M, Shiferaw A, Alamrew Z, Feleke A, Fentie T, Atnafu K: Current state of active trachoma among elementary school students in the context of ambitious national growth plan: The case of Ethiopia. Health (NY) 2013, 5(11):1768.

56. Oswald WE, Stewart AE, Kramer MR, Endeshaw T, Zerihun M, Melak B, Sata E, Gessese D, Teferi T, Tadesse Z. Active trachoma and community use of sanitation Ethiopia. Bull World Health Organ. 2017;95(4):250.

57. Emerson PM, Ngondi J, Biru E, Graves PM, Ejigsemahu Y, Gebre T, Endeshaw T, Genet A, Mosher AW, Zerihun M. Integrating an NTD with one of "the big three": combined malaria and trachoma survey in Amhara region of Ethiopia. PLoS Negl Trop Dis. 2008;2(3):e197.

58. Negash K, Macleod C, Adamu Y, Ahmed M, Ibrahim M, Ali M, Haileselassie T, Willis R, Chu BK, Dejene M. Prevalence of trachoma in the Afar Region of Ethiopia: results of seven population-based surveys from the Global Trachoma Mapping Project. Ophthalmic Epidemiol. 2018;25(sup1):3-10.

59. Adamu Y, Macleod C, Adamu L, Fikru W, Kidu B, Abashawl A, Dejene M, Chu BK, Flueckiger RM, Willis R, et al. Prevalence of Trachoma in Benishangul Gumuz Region, Ethiopia: Results of Seven Population-Based Surveys from the Global Trachoma Mapping Project. Ophthalmic Epidemiol. 2016;23(sup1):70-6.

60. Alemayehu M, Koye DN, Tariku A, Yimam K. Prevalence of active trachoma and its associated factors among rural and urban children in Dera Woreda Northwest Ethiopia: a comparative cross-sectional study. BioMed Res Int. 2015;2015.

61. Abashawl A, Macleod C, Riang J, Mossisa F, Dejene M, Willis R, Flueckiger RM, Pavluck AL, Tadesse A, Adera TH, et al. Prevalence of Trachoma in Gambella Region, Ethiopia: Results of Three Population-Based Prevalence Surveys Conducted with the Global Trachoma Mapping Project. Ophthalmic Epidemiol. 2016;23(sup1):77-83.

62. Nega A, Aklilu AR, Abdosh AT, Jelalu KB, Eskindr DZ. Prevalence and factors associated with trachoma among primary school children in Harari region Eastern Ethiopia. Ophthalmol Res. 2017;7(3):1-9.

63. Yalew KN, Mekonnen MG, Jemaneh AA. Trachoma and its determinants in Mojo and Lume districts of Ethiopia. Pan Afr Med J. 2012;13(Suppl 1).

64. Ejigu M, Kariuki MM, Ilako DR, Gelaw Y. Rapid trachoma assessment in kersa district, Southwest Ethiopia. Ethiop J Health Sci. 2013;23(1):1-9.

65. Mehari ZA. Pattern of childhood ocular morbidity in rural eye hospital Central Ethiopia. BMC Ophthalmol. 2014;14(1):50

66. Bero B, Macleod C, Alemayehu W, Gadisa S, Abajobir A, Adamu Y, Alemu M, Adamu L, Dejene M, Mekasha A. Prevalence of and risk factors for trachoma in Oromia regional state of Ethiopia: results of 79 population-based prevalence surveys conducted with the global trachoma mapping project. Ophthalmic Epidemiol. 2016;23(6):392-405.

67. Wosen A, Bekana F, Ayanos T. Prevalence of trachoma and associated risk factors among Yello elementary school students. Loma Woreda, Dawro Zone, Ethiopia: J Nursing care; 2015

68. Adera TH, Macleod C, Endriyas M, Dejene M, Willis R, Chu BK, Letamo Y, Misganaw T, Mesele T, Mekonnen E, et al. Prevalence of and Risk Factors for Trachoma in Southern Nations, Nationalities, and Peoples' Region, Ethiopia: Results of 40 Population-Based Prevalence Surveys Carried Out with the Global Trachoma Mapping Project. Ophthalmic Epidemiol. 2016:23(sup1):84-93.

69. Mengistu K, Shegaze M, Woldemichael K, Gesesew H, Markos Y. Prevalence and factors associated with trachoma among children aged 1-9 years in Zala district, gamo gofa Zone, southern ethiopia. Clin Ophthalmol (Auckland, NZ). 2016;10:1663.

70. Shaffi M, Bejiga A. Common eye diseases in children of rural community in Goro district, Central Ethiopia. Ethiop J Health Dev. 2005;19(2):148-52.

71. Alemayehu W, Melese M, Fredlander E, Worku A, Courtright P. Active trachoma in children in Central Ethiopia: association with altitude. Trans $\mathrm{R}$ Soc Trop Med Hyg. 2005;99(11):840-3.

72. Duale AB, Negussu Ayele N, Macleod CK, Kello AB, Eshetu Gezachew Z, Binegdie A, Dejene M, Alemayehu W, Flueckiger RM, Massae PA. Epidemiology of trachoma and its implications for implementing the "SAFE" strategy in Somali Region, Ethiopia: results of 14 population-based prevalence surveys. Ophthalmic Epidemiol. 2018;25(sup1):25-32.

73. Sherief ST, Macleod C, Gigar G, Godefay H, Abraha A, Dejene M, Kello AB, Belete A, Assefa Y, Willis R, et al. The Prevalence of Trachoma in Tigray
Region, Northern Ethiopia: Results of 11 Population-Based Prevalence Surveys Completed as Part of the Global Trachoma Mapping Project. Ophthalmic Epidemiol. 2016;23(sup1):94-9.

74. Mesfin MM, de la Camera J, Tareke IG, Amanual G, Araya T, Kedir AM. A community-based trachoma survey: prevalence and risk factors in the Tigray region of northern Ethiopia. Ophthalmic Epidemiol. 2006;13(3):173-81.

75. WHO/UNICEF: The Drinking Water and Sanitation Ladder. WHO/UNICEF Joint Monitoring Programme for Water Supply and Sanitatoin. WHO/ UNICEF, New York. 2016.

76. Solomon AW, Willis R, Pavluck AL, Alemayehu W, Bakhtiari A, Bovill S, Chu BK, Courtright P, Dejene M, Downs P, et al. Quality assurance and quality control in the global trachoma mapping project. Am J Trop Med Hyg. 2018; 99(4):858-63.

77. Prüss A, Mariotti SP. Preventing trachoma through environmental sanitation: a review of the evidence base. Bull World Health Organ. 2000;78(2):267-73.

78. Farrar J, Hotez P, Junghanss T, Kang G, Lalloo D, White NJ. Manson's tropical diseases E-book: Elsevier health sciences; 2013.

79. Hsieh Y-H, Bobo LD, Quinn TC, West SK. Risk factors for trachoma: 6-year follow-up of children aged 1 and 2 years. Am J Epidemiol. 2000;152(3):204-11.

80. Polack S, Kuper H, Solomon AW, Massae PA, Abuelo C, Cameron E, Valdmanis $V$, Mahande M, Foster A, Mabey D. The relationship between prevalence of active trachoma, water availability and its use in a Tanzanian village. Trans R Soc Trop Med Hyg. 2006;100(11):1075-83.

\section{Publisher's Note}

Springer Nature remains neutral with regard to jurisdictional claims in published maps and institutional affiliations.
Ready to submit your research? Choose BMC and benefit from:

- fast, convenient online submission

- thorough peer review by experienced researchers in your field

- rapid publication on acceptance

- support for research data, including large and complex data types

- gold Open Access which fosters wider collaboration and increased citations

- maximum visibility for your research: over $100 \mathrm{M}$ website views per year

At $\mathrm{BMC}$, research is always in progress.

Learn more biomedcentral.com/submissions 